\title{
Prevalence and characterization of foodborne pathogens from Australian dairy farm environments
}

\author{
Catherine M. McAuley, ${ }^{*}$ Kate McMillan, $\dagger$ Sean C. Moore, ${ }^{*}$ Narelle Fegan, ${ }^{*}$ and Edward M. Fox ${ }^{* 1}$ \\ ${ }^{*}$ Commonwealth Scientific and Industrial Research Organisation (CSIRO) Food and Nutrition, Werribee, Victoria 3030, Australia \\ †Commonwealth Scientific and Industrial Research Organisation (CSIRO) Food and Nutrition, Coopers Plains, Queensland 4108, Australia
}

\begin{abstract}
The ability of foodborne pathogens to gain entry into food supply systems remains an ongoing concern. In dairy products, raw milk acts as a major vehicle for this transfer; however, the sources of pathogenic bacteria that contaminate raw milk are often not clear, and environmental sources of contamination or the animals themselves may contribute to the transfer. This survey examined the occurrence of 9 foodborne pathogens in raw milk and environments of 7 dairy farms (3 bovine, 3 caprine, and 1 ovine farm) in summer and autumn, in Victoria, Australia. A total of 120 samples were taken from sampling points common to dairy farms, including pasture, soil, feed, water sources, animal feces, raw milk, and milk filters. The prevalence of the Bacillus cereus group, Campylobacter, Clostridium perfringens, Cronobacter, Shiga-toxigenic Escherichia coli, Listeria, Salmonella, coagulase-positive staphylococci (CPS), and Yersinia enterocolitica across the farms was investigated. The 2 most prevalent bacteria, which were detected on all farms, were the $B$. cereus group, isolated from $41 \%$ of samples, followed by $C l$. perfringens, which was isolated from $38 \%$ of samples. The highest occurrence of any pathogen was the $B$. cereus group in soil, present in $93 \%$ of samples tested. Fecal samples showed the highest diversity of pathogens, containing 7 of the 9 pathogens tested. Salmonella was isolated from 1 bovine farm, although it was found in multiple samples on both visits. Out of the 14 occurrences where any pathogen was detected in milk filters, only $5(36 \%)$ of the corresponding raw milk samples collected at the same time were positive for the same pathogen. All of the CPS were Staphylococcus aureus, and were found in raw milk or milk filter samples from 6 of the 7 farms, but not in other sample types. Pathogenic Listeria species were detected on 3 of the 7 farms, and included 4 L. ivanovii-positive samples, and 1 L. monocytogenespositive water sample. Shiga-toxigenic Escherichia coli
\end{abstract}

Received August 12, 2014.

Accepted August 31, 2014.

${ }^{1}$ Corresponding author: edward.fox@csiro.au were identified in fecal samples from 3 of the 7 farms and in a single raw milk sample. Cronobacter species were identified on 4 of the 7 farms, predominantly in feed samples. No Y. enterocolitica was detected. Results of this study demonstrate high standards of pathogen safety across the 7 farms, with a low incidence of pathogens detected in raw milk samples. Monitoring feed contamination levels may help control the spread of bacterial species such as $C l$. perfringens and B. cereus through the farm environment, which is a natural reservoir for these organisms.

Key words: dairy farm, pathogen, prevalence

\section{INTRODUCTION}

The dairy farm is a dynamic environment and it has a complex associated microbial ecology. A wide variety of bacteria have natural reservoirs among components of this ecosystem. The farm environment, however, represents a possible entry point into the food chain, primarily in terms of milk and associated dairy products that may be produced there. The occurrence of various pathogenic microorganisms on farms is therefore a concern if they are able to contaminate raw milk, which then provides entry into the food supply (Oliver et al., 2005). As such, understanding transmission routes of bacterial pathogens and spoilage organisms into raw milk is an important component in implementing an effective control strategy.

The entry route of foodborne pathogens from the dairy farm environment into raw milk may come from several different vectors, and includes the animal itself, feces, contaminated crops and feed, bedding, housing, and water (Oliver et al., 2005; Quigley et al., 2013). Effective control of this cross-contamination thus includes many considerations; for example, udder hygiene, feed contamination, hide contamination, gut colonization and fecal carriage, and control of movements of other animals, including birds and rodents, through the farm environment.

The means by which pathogenic microorganisms in raw milk enter products and are consumed was outlined effectively in a review by Oliver et al. (2005). 
Many foodborne outbreaks described were traced back to both raw and pasteurized milk. Some members of society have access to and consume raw milk, and similarly some cheeses are made from raw milk. Without a thermal inactivation step, producing pathogen-free raw milk is critical to preventing illness due to consumption of contaminated product. Pasteurization of raw milk, however, does not preclude the milk or dairy products from contamination by pathogens, which can contaminate products postprocessing at dairy processing plants. Indeed, not all pathogens are eliminated by pasteurization, and pathogens may also survive in milk that has had improper pasteurization.

The current study investigated the prevalence of $B a$ cillus cereus, Campylobacter, Clostridium perfringens, Cronobacter, Shiga-toxigenic Escherichia coli (STEC), Listeria, Salmonella, coagulase-positive staphylococci (CPS), and Yersinia enterocolitica in a range of environments common to most dairy farms, including pasture, soil, feed, and water sources, as well as animal feces, raw milk, and milk filters. The natural sources of the microorganisms investigated in this survey can be environmental, enteric, or a combination of both. Campylobacter, Salmonella, STEC, and Y. enterocolitica are all enteric foodborne pathogens (Milnes et al., 2008), of which Salmonella and STEC can survive in soil and the environment for long periods (Jay et al., 2003; Farrokh et al., 2013). Clostridium perfringens is also widespread both enterically and in soil (Bates and Bodnaruk, 2003). Similarly, soil is the ecological niche for B. cereus and Listeria (Jenson and Moir, 2003; Sutherland et al., 2003). Plants are thought to be the natural habitat for Cronobacter (Schmid et al., 2009). Staphylococcus aureus is found on the skin of humans and animals as well as being distributed in human environments (Stewart, 2003). Milk is not always the primary source of these microorganisms in the food supply, as is the case for Cronobacter, which has been more frequently isolated from animal feed and cereals (Molloy et al., 2009). Nonetheless, all of these microorganisms have been found in raw milk (Friedemann, 2007; Claeys et al., 2013; Quigley et al., 2013) and have potential to gain access to the food supply via this route.

Previous work investigating prevalence of pathogens in the dairy farm environment has typically focused on only a select few pathogens at a time, most commonly from bovine dairy farms (Cortés et al., 2006; Fox et al., 2009; Molloy et al., 2009; Bernardino-Varo et al., 2013; Bianchini et al., 2014). This survey looks at the broad occurrence of 9 foodborne pathogens from the raw milk and environments of 7 bovine, ovine, and caprine dairy farms in the summer and autumn in Victoria, Australia.

\section{MATERIALS AND METHODS}

\section{Farms and Sampling}

A total of 7 farms located throughout Victoria were included in this survey. These comprised 3 bovine farms (farms A, B, and C), and 3 caprine farms and 1 ovine farm (farms D, E, F, G; grouped together to maintain anonymity). Bovine farms were medium to large, whereas caprine and ovine farms were small to medium in size. All farms produced raw milk for further processing into milk, dairy products, or both. Farms observed a hazard analysis and critical control point (HACCP) approach to preventing contamination of the milk and milking area, including measures such as hand-wash stations, pest control measures, and sanitization. Between 7 and 11 samples were taken from each farm on each visit. A total of 120 samples were obtained over the 2 visits to each farm (as indicated in Table 1). The first visit was in early summer (December 2013) and the second visit was in early autumn (March 2014). Samples obtained comprised raw milk, milk filters, feces, soil, water, feed, and grass from pastures. The range of sample types tested depended on the target microorganism and where it was expected to be found; thus, not all 120 samples were tested for all pathogens. The raw milk samples were obtained from the bulk milk tanks except for the first visit to farm $\mathrm{F}$ and the second visit to farm $\mathrm{G}$, where the milk was obtained directly from the animals. Raw milk was additionally obtained from the bulk tank on the second visit to farm G. Milk filters were not always available at each farm; milk filters were obtained from farms A, B, $\mathrm{E}$, and $\mathrm{G}$ on both visits and from farm $\mathrm{F}$ on the second visit only. Milk filters were not available from farms C and D on either visit. Water samples were sourced from troughs on all farms as well as from a combination of dams, streams, and rainwater. All water samples were taken from surface water. Feed samples included grain, moist greenhouse grass, pellets, hay, and silage. Where multiple feeds were in use, these were included in the sample set taken when available. For bovine farm C, an additional fecal sample was taken from the animal walkway leading to the milking parlor.

\section{Sample Analysis}

A total of 9 bacterial species or genera were tested for, using ISO, Australian standard methods, or validated in-house methods, as listed in Table 2. These comprised the Bacillus cereus group (B. cereus, Bacillus mycoides, Bacillus pseudomycoides, Bacillus thuringiensis, Bacillus weihenstephanensis, Bacillus anthracis, and Bacillus 
cytotoxicus), Campylobacter species, Cl. perfringens, Cronobacter spp., STEC, Listeria spp., Salmonella spp., CPS, and $Y$. enterocolitica. All raw milk, milk filter, feces, and soil samples were tested for all 9 pathogens. Listeria monocytogenes and Staph. aureus were tested for in all samples; however, detections of the other 7 bacterial species or genera were carried out in only a subset of samples (as listed in Table 1).

Depending on the method for detection, either 10 $\mathrm{mL}$ or $10 \mathrm{~g}$ of sample or $25 \mathrm{~mL}$ or $25 \mathrm{~g}$ of sample was used as detailed below (diluted 1:10 in the relevant medium or diluent). The exceptions to this were for (1) direct count methods, where $100 \mu \mathrm{L}$ of liquid sample was plated onto duplicate plates for the neat dilution; and (2) the fresh fecal samples from farm F, where $5 \mathrm{~g}$ (visit 1) or $7.5 \mathrm{~g}$ (visit 2) was used for enrichment due to limited size of available samples. All solid samples were homogenized by placing the sample into a sterile stomacher bag, with the primary enrichment medium or diluent, and homogenized for 2 min in a Lab-blender 400 model stomacher (Seward, Worthing, UK).

For confirmation of presumptive-positive isolates, 1 of 3 different validated methods was used: real-time PCR, latex agglutination antisera assays, or biochemical confirmation (as listed in Table 2). Only confirmed positive isolates are listed in this study.

\section{Detection of Top 7 STEC}

Detection of the top 7 STEC serotypes (i.e., O26, O45, O103, O111, O121, O145, O157) was carried out by addition of $10 \mathrm{~g}$ of sample to $90 \mathrm{~mL}$ of buffered peptone water (BPW; Oxoid, Basingstoke, UK). Solid samples were mixed by stomaching for $2 \mathrm{~min}$, and mixed samples were then incubated at $42^{\circ} \mathrm{C}$ for $6 \mathrm{~h}$. Subsequent isolation was carried out using commercially available immunomagnetic separation beads according to the manufacturer's instructions. This included 2 separate bead treatments: O157-specific Dynabeads (Life Technologies, Melbourne, Australia) for E. coli O157 and Poly IMS-Top STEC beads for the top 7 STEC serotypes (Biocontrol, Bellevue, WA). Isolated bead suspensions were then plated on both cefixime tellurite sorbitol MacConkey agar (Oxoid) and Rainbow chromogenic agar plates (Biolog, Hayward, CA). Multiplex PCR based on the method developed by Paton and Paton (2002) was used to confirm the presence of the $s t x_{1}$ and $s t x_{2}$ genes; STEC isolates that contained either the $s t x_{1}$ or $s t x_{2}$ gene were then tested for serotype using a PCR method (Perelle et al., 2004), along with a validated USDA method (USDA-FSIS, 2012a). Results of this combined analysis characterized isolates as O26, O45, O103, O111, O121, O145, O157, or "nontop 7". Although the isolation method targeted the top
7 STEC serotypes, non-top 7 serotypes of STEC may also have been isolated using this method.

\section{Serotyping of Presumptive Top 7 STEC Isolates}

Determination of STEC serotypes was performed by using a PCR method (Perelle et al., 2004), along with a validated USDA method (USDA-FSIS, 2012a). Results of this combined analysis characterize isolates as O26, O45, O103, O111, O121, O145, O157 or "non-top 7".

\section{Detection of Salmonella Species}

Detection of Salmonella species was carried out by addition of $10 \mathrm{~g}$ of sample to $90 \mathrm{~mL}$ of BPW. Solid samples were mixed by stomaching for $2 \mathrm{~min}$, and mixed samples were then incubated at $42^{\circ} \mathrm{C}$ for $6 \mathrm{~h}$. Isolation was then carried out using commercially available Dynabeads (Biocontrol), specific for Salmonella. Briefly, $20 \mu \mathrm{L}$ of Dynabeads was added to $1 \mathrm{~mL}$ of enriched sample. Following bead retrieval in $250 \mu \mathrm{L}$ of PBS-Tween as per the manufacturer's instruction, 100 $\mu \mathrm{L}$ of this was added to $10 \mathrm{~mL}$ of Rappaport Vassiliadis broth (bioMérieux, Baulkam Hills, Australia) and incubated at $42^{\circ} \mathrm{C}$ for $24 \mathrm{~h}$. One hundred microliters of this culture was then plated in duplicate on xylose lysine deoxycholate agar (Oxoid) or brilliant green agar (Oxoid). Presumptive-positive isolates were confirmed using latex agglutination (Oxoid) and invA PCR (Eyigor and Carli, 2003).

\section{RESULTS}

\section{Overview}

In total, 120 samples were collected from 7 farms. Of the 9 pathogens tested for, the 2 most prevalent species, which were detected on all 7 farms, were the B. cereus group, positive in $41 \%$ of samples followed by Cl. perfringens, positive in $38 \%$ of samples (Table 1). The highest occurrence of any of the pathogens was the B. cereus group in soil, present in $93 \%$ of the samples tested. Although the greatest range of pathogens was found in feces, the highest total number of positive samples within a sample type was in soil, influenced by the frequent occurrence of the $B$. cereus group in the soil. In contrast, $Y$. enterocolitica was not detected in any of the samples tested and Campylobacter was found in only 1 bovine fecal sample on the second visit to farm A at the beginning of autumn. Testing milk filters in addition to raw milk samples increased the chance of detecting the pathogens. Out of 14 occurrences where any pathogens were detected in the milk filters, only $5(36 \%)$ of the corresponding raw milk 
Table 1. Overview of the 9 pathogens ${ }^{1}$ present in each sample type

Number $(\%)$ of positive samples

\begin{tabular}{|c|c|c|c|c|c|c|c|c|c|c|}
\hline Source & $\begin{array}{l}\text { Bacillus } \\
\text { cereus } \\
\text { group }\end{array}$ & Campylobacter & $\begin{array}{l}\text { Clostridium } \\
\text { perfringens }\end{array}$ & Cronobacter & STEC & $\begin{array}{l}\text { Pathogenic } \\
\text { Listeria }\end{array}$ & Salmonella & CPS & $\begin{array}{c}\text { Yersinia } \\
\text { enterocolitica }\end{array}$ & $\begin{array}{c}\text { Total positive } \\
\text { samples }\end{array}$ \\
\hline Milk filter $(\mathrm{n}=9)$ & $3(33)$ & $0(0)$ & $3(33)$ & $1(11)$ & $0(0)$ & $1(11)$ & $2(22)$ & $5(56)$ & $0(0)$ & $14 / 81(17)$ \\
\hline Raw milk $(\mathrm{n}=15)$ & $0(0)$ & $0(0)$ & $2(13)$ & $0(0)$ & $1(7)$ & $0(0)$ & $1(7)$ & $5(33)$ & $0(0)$ & $9 / 135(7)$ \\
\hline Feces $(\mathrm{n}=16)$ & $10(63)$ & $1(6)$ & $8(50)$ & $1(6)$ & $3(19)$ & $1(6)$ & $2(13)$ & $0(0)$ & $0(0)$ & $26 / 144(18)$ \\
\hline Soil $(\mathrm{n}=14)$ & $13(93)$ & $0(0)$ & $9(64)$ & $0(0)$ & $0(0)$ & $0(0)$ & $2(14)$ & $0(0)$ & $0(0)$ & $24 / 126(19)$ \\
\hline Water $(\mathrm{n}=31)$ & $\mathrm{NT}^{2}$ & $\mathrm{NT}$ & NT & NT & $0(0)$ & $2(6)$ & $2(6)$ & $0(0)$ & NT & $4 / 124(3)$ \\
\hline Feed $(\mathrm{n}=21)^{3}$ & $2 / 14(14)$ & NT & $4 / 14(29)$ & $6 / 16(38)$ & $0 / 16(0)$ & $0 / 21(0)$ & $2 / 16(13)$ & $0 / 21(0)$ & $0 / 13(0)$ & $14 / 131(11)$ \\
\hline Grass (pasture) $(\mathrm{n}=14)$ & $\mathrm{NT}$ & NT & NT & $\mathrm{NT}$ & NT & $1(7)$ & $\mathrm{NT}$ & $0(0)$ & NT & $1 / 28(4)$ \\
\hline Total positive samples & $28 / 6(41)$ & $1 / 54(2)$ & $26 / 68(38)$ & $8 / 70(11)$ & $4 / 101(4)$ & $5 / 120(4)$ & $11 / 101(11)$ & $10 / 120(8)$ & $0 / 67(0)$ & \\
\hline
\end{tabular}

${ }^{1}$ STEC = Shiga-toxigenic Escherichia coli; CPS = coagulase-positive staphylococci.

${ }^{2} \mathrm{NT}=$ not tested.

${ }^{3}$ Not all 21 feed samples were tested for each organism; total samples tested are listed for each pathogen as number positive/total.

Table 2. Detection and confirmation methods used in this study

\begin{tabular}{|c|c|c|c|c|}
\hline \multirow[b]{2}{*}{ Target bacteria } & \multicolumn{2}{|l|}{ Detection method } & \multicolumn{2}{|c|}{ Confirmation method } \\
\hline & Method & Type & Gene target/method & Reference \\
\hline $\begin{array}{l}\text { Bacillus cereus group } \\
\text { Campylobacter species } \\
\text { Clostridium perfringens } \\
\text { Cronobacter } \text { species } \\
\text { STEC } \\
\text { Listeria } \text { species } \\
\text { Salmonella } \text { species } \\
\text { Coagulase-positive staphylococci } \\
\text { Yersinia enterocolitica }\end{array}$ & $\begin{array}{l}\text { AS 5013.2-2007; Standards Australia (2007) } \\
\text { AS 5013.6-2004; Standards Australia (2004a) } \\
\text { AS 5013.16-2006; Standards Australia (2006) } \\
\text { AS 5013.13(Int)-2010; Standards Australia (2010) } \\
\text { As described } \\
\text { ISO 11290-1:1996(E); ISO (1996) } \\
\text { As described } \\
\text { AS 5013.12.1-2004; Standards Australia (2004b) } \\
\text { ISO 10273; ISO (2003) }\end{array}$ & $\begin{array}{l}\text { Direct count } \\
\text { Enrichment } \\
\text { Direct count } \\
\text { Enrichment } \\
\text { Enrichment } \\
\text { Enrichment } \\
\text { Enrichment } \\
\text { Direct count } \\
\text { Enrichment }\end{array}$ & $\begin{array}{l}\text { Hemolysin gene } \\
\text { lpxA } \\
\text { cpa } \\
\text { Macromolecular synthesis (MMS) operon } \\
\text { stx }_{1}, \text { stx }_{2}, \text { eae, ehx } \\
\text { Biochemical }^{2} \\
\text { invA and latex agglutination } \\
\text { fem } A^{4} \\
\text { ail }\end{array}$ & $\begin{array}{l}\text { Wang et al. (1997) } \\
\text { Klena et al. (2004) } \\
\text { Chon et al. (2012) } \\
\text { Seo and Brackett (2005) } \\
\text { Paton and Paton (2002) } \\
\text { - } \\
\text { Eyigor and Carli (2003) } \\
\text { Mehrotra et al. (2000) } \\
\text { Thisted Lambertz et al. (2008) }\end{array}$ \\
\hline $\begin{array}{l}{ }^{1} \text { Shiga-toxigenic Escherichia coli; } \\
{ }^{2} \text { Microbact Listeria } 12 \mathrm{~L} \text { (Oxoid, } \\
{ }^{3} \text { Oxoid Salmonella test kit (Oxoic } \\
{ }^{4} \text { For confirmation of Staphylococc }\end{array}$ & $\begin{array}{l}\text { his method targeted the top } 7 \text { serotypes, although } \\
\text { asingstoke, UK). } \\
\text { s aureus. }\end{array}$ & lor & non-top 7 STEC. & \\
\hline
\end{tabular}


Table 3. Presence of each pathogen ${ }^{1}$ on each farm (A to G)

\begin{tabular}{|c|c|c|c|c|c|c|c|c|c|}
\hline Farm & \multicolumn{8}{|c|}{ Isolations of each pathogen on each farm } & $\begin{array}{l}\text { Total number of } \\
\text { pathogen types } \\
\text { on each farm }\end{array}$ \\
\hline A & 3 & 1 & 4 & 4 & 0 & 0 & 11 & 1 & 6 \\
\hline B & 5 & 0 & 3 & 1 & 0 & 2 & 0 & 2 & 5 \\
\hline $\mathrm{C}$ & 5 & 0 & 3 & 0 & 1 & 1 & 0 & 1 & 5 \\
\hline $\mathrm{F}$ & 6 & 0 & 6 & 1 & 0 & 0 & 0 & 0 & 3 \\
\hline $\mathrm{G}$ & 2 & 0 & 1 & 0 & 1 & 0 & 0 & 3 & 4 \\
\hline
\end{tabular}

${ }^{1} \mathrm{STEC}=$ Shiga-toxigenic Escherichia coli; $\mathrm{CPS}=$ coagulase-positive staphylococci.

samples collected at the same time as the filters were positive for the same pathogen. It should be noted that for the enrichment-based methods (i.e., for detection of Campylobacter, Cronobacter, STEC, Listeria, Salmonella and $Y$. enterocolitica), the amount of fecal sample from farm $\mathrm{F}$ was less than the optimum amount of 10 or $25 \mathrm{~g}$, so very low levels of contamination may have remained undetected.

Across all of the farms, farms $\mathrm{A}$ and $\mathrm{E}$ had the greatest number of pathogen types, whereas farm $\mathrm{F}$ had the least (Table 3 ). The 3 farms with the fewest pathogen types, farms D, F, and G, were all caprine or ovine farms. Bacillus cereus and $\mathrm{Cl}$. perfringens were widespread and distributed consistently across all of the farms except farm $G$, which had a lower occurrence compared with the other farms. Campylobacter and Salmonella were only present on farm A, although the other enteric pathogen, STEC, was not detected on this farm.

\section{Bacillus cereus}

The $B$. cereus group was detected in both bovine and caprine-ovine samples and was isolated from the soil on each of the farms (Table 4). The counts in positive samples ranged from $5.0 \times 10^{2}$ to $2.7 \times 10^{5} \mathrm{cfu} / \mathrm{g}$ or $\mathrm{mL}$, with a median of $5.4 \times 10^{3} \mathrm{cfu} / \mathrm{g}$ or $\mathrm{mL}$ (Table 5 ). Both soil samples were positive from farms A, B, C, D, $\mathrm{F}$, and $\mathrm{G}$, but only on the second sampling from Farm E. On the first visit, B. cereus was isolated in the feces from farms $\mathrm{C}$ and $\mathrm{F}$, whereas on the second visit, the feces tested positive from all of the farms except farm G. Although B. cereus group bacteria were found in the milk filters, they were not detected in any of the raw milk samples. The Bacillus cereus group was identified in feed samples (grain) from all caprine-ovine farms on the second visit but not at the bovine farms.

\section{Clostridium perfringens}

Clostridium perfringens was isolated at least once from all farms (Table 6), with the highest occurrence (64\%) being in soil samples (Table 1). Blackening of the medium prevented accurate counts in some instances; however, the counts obtained ranged from $1 \mathrm{cfu} / \mathrm{g}$ or $\mathrm{cfu} / \mathrm{mL}$ to approximately $1 \times 10^{5} \mathrm{cfu} / \mathrm{g}$ or $\mathrm{cfu} / \mathrm{mL}$, with a median of $1 \times 10^{3} \mathrm{cfu} / \mathrm{g}$ or $\mathrm{cfu} / \mathrm{mL}$ (Table 5 ). All of the occurrences in the raw milk and milk filters were from the second visit to the farms. Of the 3 farms that had positive milk filters, $C l$. perfringens was also

Table 4. Prevalence of Bacillus cereus group on each farm (A to G) ${ }^{1}$

\begin{tabular}{|c|c|c|c|c|c|c|c|c|c|c|c|c|c|c|}
\hline \multirow[b]{3}{*}{ Source } & \multicolumn{6}{|c|}{ Bovine } & \multicolumn{8}{|c|}{ Caprine and Ovine } \\
\hline & \multicolumn{2}{|c|}{$\mathrm{A}$} & \multicolumn{2}{|c|}{ B } & \multicolumn{2}{|c|}{$\mathrm{C}$} & \multicolumn{2}{|c|}{$\mathrm{D}$} & \multicolumn{2}{|c|}{$\mathrm{E}$} & \multicolumn{2}{|c|}{$\mathrm{F}$} & \multicolumn{2}{|c|}{$\mathrm{G}$} \\
\hline & $\mathrm{S} 1$ & $\mathrm{~S} 2$ & $\mathrm{~S} 1$ & $\mathrm{~S} 2$ & $\mathrm{~S} 1$ & $\mathrm{~S} 2$ & $\mathrm{~S} 1$ & $\mathrm{~S} 2$ & $\mathrm{~S} 1$ & $\mathrm{~S} 2$ & $\mathrm{~S} 1$ & $\mathrm{~S} 2$ & $\mathrm{~S} 1$ & $\mathrm{~S} 2$ \\
\hline Milk filter $(\mathrm{n}=9)$ & - & - & - & + & $\mathrm{NT}^{2}$ & $\mathrm{NT}$ & NT & NT & + & - & NT & + & - & - \\
\hline Raw milk $(\mathrm{n}=15)$ & - & - & - & - & - & - & - & - & - & - & - & - & - & - \\
\hline Feces $(n=16)$ & - & + & + & + & + & $+{ }^{3}$ & - & + & - & + & + & + & - & - \\
\hline Soil $(\mathrm{n}=14)$ & + & + & + & + & + & + & + & + & - & + & + & + & + & + \\
\hline Feed $(\mathrm{n}=14)$ & - & - & - & - & - & - & - & + & - & - & - & + & - & - \\
\hline
\end{tabular}

${ }^{1}$ S1 = December 2013 sampling; S2 = March 2014 sampling.

${ }^{2} \mathrm{NT}=$ not tested.

${ }^{3}$ Detected in both fecal samples taken on this visit. 
Table 5. Enumeration (cfu/g or $\mathrm{cfu} / \mathrm{mL}$ ) of bacteria in positive samples

\begin{tabular}{lccc}
\hline Organism & $\begin{array}{c}\text { Minimum } \\
\text { number detected }\end{array}$ & $\begin{array}{c}\text { Maximum } \\
\text { number detected }\end{array}$ & $\begin{array}{c}\text { Mean number } \\
\text { detected }\end{array}$ \\
\hline Bacillus cereus group & $5.0 \times 10^{2}$ & $2.7 \times 10^{5}$ & $5.4 \times 10^{3}$ \\
Clostridium perfringens & 1 & $1 \times 10^{5}$ & $1 \times 10^{3}$ \\
Coagulase-positive staphylococci & 40 & $5 \times 10^{4}$ & $2.5 \times 10^{3}$ \\
\hline
\end{tabular}

detected in raw milk in the case of farm $\mathrm{F}$. It was found in the soil on all of the farms except farm G: on both samplings at farms $\mathrm{D}, \mathrm{E}$, and $\mathrm{F}$ and on only 1 visit to farms A, B, and $\mathrm{C}$. The presence of $\mathrm{Cl}$. perfringens in the feed samples occurred in the grain on the caprineovine group farms, on farms $\mathrm{D}$ and $\mathrm{F}$ on the first visit and farms D and $\mathrm{G}$ on the second visit.

\section{Cronobacter Species}

Cronobacter species were isolated in 8 samples from both bovine and caprine-ovine farms, with the majority of isolates $(38 \%)$ found in feed samples (Table 1). Cronobacter were detected in the grain samples on the first visit to farms $\mathrm{A}$ and $\mathrm{B}$ and the second visit to farms A and E. Cronobacter species were also isolated from the grass feed from farm $\mathrm{E}$ on the second visit. Cronobacter were isolated from the milk filter at the first visit to farm $\mathrm{E}$ and from the bovine fecal sample on the second visit to farm A, but were not isolated in the raw milk from farm $\mathrm{E}$ at the time the milk filter was collected.

\section{STEC}

Shiga-toxigenic E. coli were isolated from $4 \%$ of all the samples (Table 1). They were isolated on the second visit in 4 samples, with 3 of them being feces. The STEC from bovine farm $\mathrm{C}$ contained $s t x_{1}$, whereas STEC from fecal samples on the caprine-ovine farms contained $s t x_{1}$ (farm E) and the $s t x_{2}$ (farm $\mathrm{G}$ ). The raw milk from farm E also contained STEC with stx. . A summary of the STEC isolates is given in Table 7. Only
1 isolate belonged to the top 7 serotypes, as determined by PCR (an O26 isolate) - the other 3 serotypes did not belong to the top 7 and are currently unknown.

\section{Pathogenic Listeria Species}

Listeria species were found in $18 \%$ of all samples; however, the pathogenic species of L. monocytogenes $(\mathrm{n}=1)$ and $L$. ivanovii $(\mathrm{n}=4)$ were only isolated from $4 \%$ of samples (Table 1). All 4 of the L. ivanovii isolates were obtained on the first visit to farms B ( $\mathrm{n}=$ 2 isolates) and $\mathrm{E}(\mathrm{n}=2$ isolates). The $L$. ivanovii from farm $B$ were found in the milk filter and in water from a stream. On farm E, the L. ivanovii were found in feces and pasture grass. The only sample found to contain L. monocytogenes was obtained from dam water on the second visit to farm C.

\section{Salmonella Species}

Salmonella were found in $11 \%$ of all samples and in all sample types tested (Table 1); however, they were only isolated from farm A. Salmonella were obtained from the milk filter, feces, soil, and feed on both visits. On the first visit, Salmonella was also found in the raw milk. Trough water and dam water were positive on the second visit.

\section{CPS}

All 120 samples were tested for CPS, and CPS were detected in $8 \%$ of the samples (Table 1) and on all farms except farm F. All of the CPS isolated were

Table 6. Prevalence of Clostridium perfringens group on each farm (A to G) ${ }^{1}$

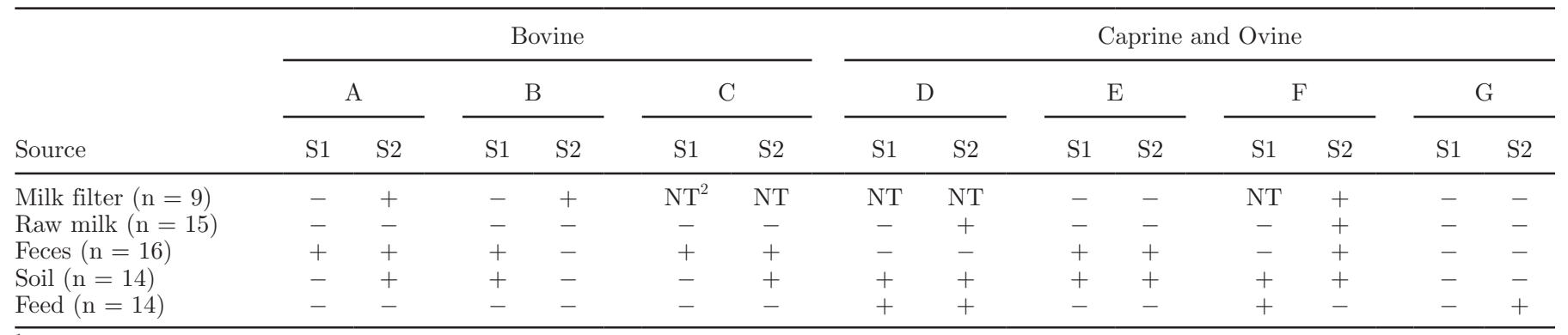

${ }^{1}$ S1 = December 2013 sampling; S2 = March 2014 sampling.

${ }^{2} \mathrm{NT}=$ not tested. 
Table 7. Shiga-toxigenic Escherichia coli (STEC) isolates detected in this study

\begin{tabular}{lllllll}
\hline & & & \multicolumn{4}{c}{ Gene } \\
\cline { 3 - 6 } Sample & Farm & Serotype & stx & stx & eae & ehx \\
\hline Raw milk & E & Not top 7 & + & - & - & + \\
Feces & C & O26 & + & - & + & - \\
Feces & E & Not top 7 & + & - & - & + \\
Feces & G & Not top 7 & - & + & - & + \\
\hline
\end{tabular}

${ }^{1}$ Not serotype O26, O45, O103, O111, O121, O145, or O157.

Staph. aureus, and they were detected only in the raw milk and milk filter samples and not in any of the other sample types. The counts ranged from 40 to $5 \times 10^{4}$ $\mathrm{cfu} / \mathrm{mL}$, with a median of $2.5 \times 10^{3} \mathrm{cfu} / \mathrm{mL}$. Counts were not available on the milk filter sample from farm $\mathrm{E}$ due to a high level of background flora on the selective agar plates. Staphylococcus aureus were isolated from both the raw milk and milk filters on farms B, E, and $\mathrm{G}$ but only in the milk filter from farm A and raw milk from farm D. Milk filters were not available from farms C and D.

\section{DISCUSSION}

Many factors contribute to the microbiological quality of food products intended for human consumption. Various food safety control measures can be implemented to produce a product that is deemed safe for consumption. In the case of dairy products, one such measure that influences this outcome is the microbiological quality of raw milk. Although many pathogens or spoilage organisms can be controlled through processing of the food product itself, some organisms are particularly resistant to control measures such as pasteurization (e.g., spore-forming bacteria such as the $B$. cereus group and $C l$. perfringens). Another consideration is cross-contamination of food production environments by microorganisms harbored in the raw milk itself. For these reasons, excluding these bacteria from raw milk is an important component to ensuring pathogen-free, safe dairy food products. Understanding the ecology of key target microorganisms in the dairy farm environment can provide insight into where measures can be implemented to control these microorganisms. It can also help identify potentially problematic aspects such as high prevalence, or persistent contamination of particular points in the dairy farm environment.

Although $B$. cereus group bacteria were found in the soil on all farms and in feces from all farms except farm $G$, these species did not widely contaminate raw milk during the sampling times examined in this study. Bacillus cereus group bacteria were not isolated from any of the raw milk samples but were found in the milk filters from 3 of the 5 farms tested. The milk filters may have prevented contamination of the milk itself; however, as bacteria are concentrated on the smaller area of the milk filter, they can be easier to detect in these samples than in the related milk, where they are typically more dilute. Bacillus cereus group bacteria have previously been found in both cow and goat raw milks (Quigley et al., 2013), although outbreaks of foodborne illness due to the $B$. cereus group in dairy products are infrequent. In a 10-yr analysis of foodborne outbreaks in the United States, only 1 suspected outbreak of illness due to $B$. cereus was attributed to a dairy product (Bennett et al., 2013). No foodborne outbreaks in Australia were attributed to $B$. cereus over the period from 1995 to 2009 (Dalton et al., 2004; Kirk et al., 2010).

Foodborne illnesses due to $\mathrm{Cl}$. perfringens are not notifiable in Australia (OzFoodNet Working Group, 2012), making it more difficult to track incidents. The food vehicle was unknown in the majority of outbreaks that have occurred in Australia due to Cl. perfringens (OzFoodNet Working Group, 2012); however, a single outbreak in 1997 was attributed to contaminated cheese sauce (NSWFA, 2009). Between 1998 and 2008 in the United States, only 1 confirmed and 1 suspected foodborne outbreak of $C l$. perfringens have been attributed to dairy products, with most patients with $\mathrm{Cl}$. perfringens experiencing diarrhea and abdominal cramps (Bennett et al., 2013). Clostridium perfringens has been detected in both bovine and ovine raw milks (Quigley et al., 2013). In the current work, $\mathrm{Cl}$. perfringens was detected in raw milk and milk filters from farms in the caprine-ovine group, as well as in milk filters from both bovine farms tested. Given that it was also found in feces and soil on most of the bovine and caprine-ovine farms, this is not surprising. The organism was also detected in 4 of the feed samples tested (29\%). In addition, 2 of the feed samples containing $C l$. perfringens also contained B. cereus. Both of these spore-formers are found in soil and may have contaminated grains during production. Contaminated grain may represent a vector for colonization of the animal gut by $\mathrm{Cl}$. perfringens; however, the results of this study did not appear to correlate positive feed with fecal shedding. Nonetheless, high contamination levels in feed may be a risk factor for spread of the organism through the farm 
environment, and may represent a control point in limiting the exposure of animals to the organism; although feed contamination levels were generally low, one grain feed sample contained between $10^{4}$ and $10^{5} \mathrm{cfu} / \mathrm{g}$.

Cronobacter species have garnered attention due to fatal infections in neonates associated with the use of powdered infant formula (PIF); however, the source of contamination of the PIF can be either from the PIF itself or from contamination of the external environmental during preparation or delivery of the food (Holý and Forsythe, 2013). Cronobacter species have been isolated from the milk powder used to produce PIF as well as various environments within and external to milk powder manufacturing plants (Craven et al., 2010; Jacobs et al., 2011). Molloy et al. (2009) investigated Irish farm environments to identify potential sources of contamination of raw milk and PIF. They found that $67 \%$ of feed and grain samples on a bovine dairy farm were positive for Cronobacter, whereas the pathogen was not detected in feces, trough water, or grain samples. The current study had similar results, with the majority of the isolates found in feed samples from both bovine and caprine-ovine farms, although Cronobacter was also detected in a single bovine fecal sample. Additionally, this study isolated Cronobacter from the milk filter and a moist grass feed sample from farm E. The presence in the grass feed is notable as Cronobacter is thought to have adapted to dry environments and is out-competed by other microflora in moister environments (Molloy et al., 2009). To our knowledge, this is the first study that has looked at Cronobacter in caprine and ovine raw milk and farm environments, which is important given that caprine and ovine milks are also used for milk powders or specialty PIF.

A recent international review was conducted on STEC in dairy production and it noted that cows, sheep, and goats can all be healthy carriers of STEC and that shedding of STEC in the feces is sporadic but can continue for several months (Farrokh et al., 2013). Contaminated environmental sources such as soil, pasture, feed, and water can introduce or recirculate STEC to farm animals (Farrokh et al., 2013). Contamination of dairy products in the dairy plant is rare, and contamination of raw milk is predominantly from contaminated feces, although mastitis due to STEC is also a possible source of milk contamination (Farrokh et al., 2013). The review found that, on average, 0 to $2 \%$ of raw bovine, caprine, and ovine milk samples were contaminated with STEC, with levels as high as $4.8 \%$ in bovine, $12.6 \%$ in caprine, and $13.8 \%$ for caprine raw milk (Farrokh et al., 2013). It is important to note, however, that the methods used in the current study were directed to isolation of the top 7 STEC serotypes (although as demonstrated in the results, 3 of the 4 STEC isolated were not top 7). These 7 serotypes, which include E. coli $\mathrm{O} 157$ and the 6 serotypes of STEC most commonly associated with clinical disease in the United States (Brooks et al., 2005), have been classified as food adulterants by the USDA (USDA-FSIS, 2012b). Studies on the occurrence of STEC in Australian raw milk have not been published. In the current study, $E$. coli containing the $s t x_{1}$ or $s t x_{2}$ genes were found in feces on 3 separate farms in the summer sampling time only (Table 7 ). Of the 15 raw milk samples tested, 1 raw milk sample from a caprine-ovine farm was positive for STEC, comprising $7 \%$ of the raw milk samples. If raw milk is usually contaminated by STEC from fecal material and shedding in the feces is sporadic, then a much larger study over a greater period of time would be required to present a more precise indication of STEC in Australian raw milk. Of the 4 isolates in this study, 3 did not possess $s t x_{2}$, which is generally considered to be associated with more severe disease and a higher associated rate of hemolytic-uremic syndrome (Friedrich et al., 2002). The isolate that did possess st $x_{2}$ did not possess the eae gene, which encodes the outer membrane adhesin intimin; this virulence marker is associated with outbreak strains and those associated with more severe forms of illness. Indeed, only 1 of the isolates contained the eae gene. Taken together, these results suggest that the STEC isolates found in this study are less likely to be associated with outbreaks or more severe forms of disease; however, it should be noted that it does not preclude them from the ability to cause illness (Bonnet et al., 1998).

Pathogenic Listeria were found in relatively few samples (4\%), with L. monocytogenes being detected in only 1 water sample from a bovine farm and $L$. ivanovii found in 4 other samples at 1 bovine farm and 1 from the caprine-ovine group. Listeria monocytogenes was not detected in any of the raw milk samples in this study. Studies of the prevalence of L. monocytogenes in milk show a wide range of incidence: it has been found in 0 to $10.2 \%$ and up to $45 \%$ of raw bovine milk in Europe (Claeys et al., 2013), and in 2.7 to $7 \%$ of raw milk in North America (Oliver and Murinda, 2011). In contrast to the environmental samples in the current study, Fox et al. (2009) found L. monocytogenes in $60 \%$ of surface run-off water and $50 \%$ of fecal and debris samples in the summer. Further investigations in late winter and early spring found L. monocytogenes in $17 \%$ of trough water, $12 \%$ of fecal samples, and $3 \%$ of soil samples (Fox et al., 2009). The pathogenic Listeria species detected most frequently in the current study was L. ivanovii, which is generally considered to be an animal pathogen and rarely associated with human infection (Czuprynski et al., 2010; Guillet et al., 2010). It has previously been isolated from brined white cheese 
(Osaili et al., 2012). Although it is not significant in terms of human public health, control of its presence on farms could be important to help prevent potential infection of the animals. Although it was identified on the first visit on 2 of the farms, it was not isolated on these farms on the second visit, suggesting that there may not be any significant problem with persistence in these environments or that occurrence may be seasonal. This may be reflected in the decrease in prevalence from $27 \%$ of samples positive in summer to $8 \%$ positive in autumn.

Staphylococcus aureus has been extensively researched as a cause of bovine mastitis, and several studies have examined various environmental sites within the dairy environment, although data on pasture and soil are limited. Roberson et al. (1994) found Staph. aureus in $2 \%$ of water samples and $1.5 \%$ of feed samples on bovine dairy farms, with grain comprising the majority of the positive feed samples. In a study of ovine milk, CPS were detected in $14.9 \%$ of the milk samples, of which $98.7 \%$ of isolates were Staph. aureus (Linage et al., 2012). Genotyping Staph. aureus isolated from milk, cheese, ewes, and humans indicates that infected mammary glands are the main source of Staph. aureus in ovine milk (Vautor et al., 2003). In the current study, all of the CPS were Staph. aureus, which were found in $33 \%$ of the raw milk samples and $44 \%$ of the milk filters but not isolated from any of the water, soil, or pasture samples. Further investigation is needed to determine the factors relating to the presence of Staph. aureus in raw milk and milk filters in the current study, which may be from environmental contamination or crosscontamination from the teats, or may in some cases be due to subclinical infection of the animals with Staph. aureus. Such work may identify where controls may be implemented to reducing the burden of Staph. aureus in raw milk; for example, whether improved udder hygiene could improve control of the organism.

The occurrence of Salmonella in farm environments varies between studies. A year-long surveillance of Salmonella species identified the organism in $12.5 \%$ of feed mix and $10.4 \%$ of soil samples on bovine dairy farms (Rodriguez et al., 2006), whereas a survey in spring and early summer did not detect Salmonella in soil or water (Toth et al., 2013). In the current study, Salmonella was widespread on 1 bovine farm, where it was detected at both sampling times; however, it was not detected on the other bovine farms. Salmonella has been found in raw bovine and ovine milk (Quigley et al., 2013), although other studies have not detected Salmonella in caprine raw milk (Muehlherr et al., 2003; Cortés et al., 2006). The present study did not isolate Salmonella in the raw milk or any of the other samples on the caprine-ovine farms. The widespread occurrence of
Salmonella on 1 farm but not on all farms suggests that conditions on that farm may have been more favorable to the survival of Salmonella. Other animals, such as birds and rodents, have been implicated as important transmission vectors for Salmonella into and around the farm environment (Andrés-Barranco et al., 2014), which may contribute to the introduction and dissemination of the organism through this particular farm environment.

In the current study, Campylobacter was found in only 1 bovine fecal sample, but not in the raw milk or milk filter from that farm. Campylobacter is known to be found in the feces of cattle, sheep, and goats (Manser and Dalziel, 1985; Harvey et al., 2004; Schilling et al., 2012). Interestingly, of 12 recorded dairy outbreaks in Australia over the period from 1995 to 2009, 6 were attributed to Campylobacter, with unpasteurized milk being implicated as the food vector (Dalton et al., 2004; NSWFA, 2009; Kirk et al., 2010). Results of this study, however, suggest that the prevalence of the organism in the farm environments tested is low $(<2 \%)$. No $Y$. enterocolitica isolates were detected in any of the samples tested from any of the farms in this study.

We found no obvious seasonal variation recorded among the early summer and early autumn sampling times, with the exception of a few observations: L. ivanovii was only identified in the summer sampling and STEC isolation only occurred in the autumn sampling. Similarly, we did not observe any exclusivity in the association of any pathogen with either the bovine or the caprine-ovine farms, although the only farm where Salmonella was detected was a bovine farm. Further work is needed to explore this association in greater detail.

\section{CONCLUSIONS}

This study provided insights into the prevalence of pathogenic bacteria across dairy farms and suggested, overall, a high quality of milking hygiene across the farms in this study. The incidence of STEC, L. monocytogenes, Campylobacter and Y. enterocolitica was low across all farms, and Salmonella was detected on only a single farm. This study highlighted the greater incidence of $B$. cereus group bacteria and $C l$. perfringens across the dairy environment and an association of Staph. aureus primarily with raw milk. This work indicates areas where future efforts may be applied to help control specific organisms, in particular the B. cereus group, Cl. perfringens, Staph. aureus, and Salmonella.

\section{ACKNOWLEDGMENTS}

This work was co-funded by the Department of Primary Industries Victoria (East Melbourne, Australia) 
and the Commonwealth Scientific and Industrial Research Organisation (CSIRO, Weribee, Australia). The authors sincerely acknowledge the support of the dairy farmers involved in this survey who made this study possible. The authors thank Marie Collier and Sieh Ng (both of CSIRO) for the collaborative effort in the assistance of project work.

\section{REFERENCES}

Andrés-Barranco, S., J. P. Vico, V. Garrido, S. Samper, S. HerreraLeón, C. de Frutos, and R. D. Mainar-Jaime. 2014. Role of wild bird and rodents in the epidemiology of subclinical Salmonellosis in finishing pigs. Foodborne Pathog. Dis. 11:698-697.

Bates, J. R., and P. W. Bodnaruk. 2003. Clostridium perfringens. Pages 479-504 in Foodborne Microorganisms of Public Health Significance. 6th ed. A. D. Hocking, ed. Australian Institute of Food Science Technology (NSW Branch) Food Microbiology Group, Sydney, NSW, Australia.

Bennett, S. D., K. A. Walsh, and L. H. Gould. 2013. Foodborne disease outbreaks caused by Bacillus cereus, Clostridium perfringens, and Staphylococcus aureus - United States, 1998-2008. Clin. Infect. Dis. 57:425-433.

Bernardino-Varo, L., E. I. Quiñones-Ramírez, F. J. Fernández, and C. Vázquez-Salinas. 2013. Prevalence of Yersinia enterocolitica in raw cow's milk collected from stables of Mexico City. J. Food Prot. 76:694-698.

Bianchini, V., L. Borella, V. Benedetti, A. Parisi, A. Miccolupo, E. Santoro, C. Recordati, and M. Luini. 2014. Prevalence in bulk tank milk and epidemiology of Campylobacter jejuni in dairy herds in Northern Italy. Appl. Environ. Microbiol. 80:1832-1837.

Bonnet, R., B. Souweine, G. Gauthier, C. Rich, V. Livrelli, J. Sirot, B. Joly, and C. Forestier. 1998. Non-O157:H7 Stx ${ }_{2}$-producing Escherichia coli strains associated with sporadic cases of hemolyticuremic syndrome in adults. J. Clin. Microbiol. 36:1777-1780.

Brooks, J. T., E. G. Sowers, J. G. Wells, K. D. Greene, P. M. Griffin, R. M. Hoekstra, and N. A. Strockbine. 2005. Non-O157 Shiga toxin-producing Escherichia coli infections in the United States, 1983-2002. J. Infect. Dis. 192:1422-1429.

Chon, J.-W., J.-S. Park, J.-Y. Hyeon, C. Park, K.-Y. Song, K.-W. Hong, I.-G. Hwang, H.-S. Kwak, and K.-H. Seo. 2012. Development of real-time PCR for the detection of Clostridium perfringens in meats and vegetables. J. Microbiol. Biotechnol. 22:530-534.

Claeys, W. L., S. Cardoen, G. Daube, J. De Block, K. Dewettinck, K. Dierick, L. De Zutter, A. Huyghebaert, H. Imberechts, P. Thiange, Y. Vandenplas, and L. Herman. 2013. Raw or heated cow milk consumption: Review of risks and benefits. Food Contr. 31:251-262.

Cortés, C., R. de la Fuente, A. Contreras, A. Sánchez, J. C. Corrales, S. Martínez, and J. A. Orden. 2006. A survey of Salmonella spp and Campylobacter spp in dairy goat faeces and bulk tank milk in the Murcia region of Spain. Ir. Vet. J. 59:391-393.

Craven, H. M., C. M. McAuley, L. L. Duffy, and N. Fegan. 2010. Distribution, prevalence and persistence of Cronobacter (Enterobacter sakazakii) in the nonprocessing and processing environments of five milk powder factories. J. Appl. Microbiol. 109:1044-1052.

Czuprynski, C. J., S. Kathariou, and K. Poulsen. 2010. Listeria. Pages 167-187 in Pathogenesis of Bacterial Infections in Animals. 4th ed. C. L. Gyles, J. F. Prescott, J. G. Songer, and C. O. Thoen, ed. Wiley-Blackwell, Ames, IA.

Dalton, C. B., J. Gregory, M. D. Kirk, R. J. Stafford, R. Givney, E. Kraa, and D. Gould. 2004. Foodborne disease outbreaks in Australia, 1995 to 2000. Commun. Dis. Intell. Q. Rep. 28:211-224.

Eyigor, A., and K. T. Carli. 2003. Rapid detection of Salmonella from poultry by real-time polymerase chain reaction with fluorescent hybridization probes. Avian Dis. 47:380-386.

Farrokh, C., K. Jordan, F. Auvray, K. Glass, H. Oppegaard, S. Raynaud, D. Thevenot, R. Condron, K. De Reu, A. Govaris, K. Heggum, M. Heyndrickx, J. Hummerjohann, D. Lindsay, S. Miszc- zycha, S. Moussiegt, K. Verstraete, and O. Cerf. 2013. Review of Shiga-toxin-producing Escherichia coli (STEC) and their significance in dairy production. Int. J. Food Microbiol. 162:190-212.

Fox, E., T. O'Mahony, M. Clancy, R. Dempsey, M. O'Brien, and K. Jordan. 2009. Listeria monocytogenes in the Irish dairy farm environment. J. Food Prot. 72:1450-1456.

Friedemann, M. 2007. Enterobacter sakazakii in food and beverages (other than infant formula and milk powder). Int. J. Food Microbiol. 116:1-10.

Friedrich, A. W., M. Bielaszewska, W. L. Zhang, M. Pulz, T. Kuczius, A. Ammon, and H. Karch. 2002. Escherichia coli harboring Shiga toxin 2 gene variants: Frequency and association with clinical symptoms. J. Infect. Dis. 185:74-84.

Guillet, C., O. Join-Lambert, A. Le Monnier, A. Leclercq, F. Mechaï, M.-F. Mamzer-Bruneel, M. K. Bielecka, M. Scortti, O. Disson, P. Berche, J. Vasquez-Boland, O. Lortholary, and M. Lecuit. 2010. Human listeriosis caused by Listeria ivanovii. Emerg. Infect. Dis. $16: 136-138$.

Harvey, R. B., R. E. Droleskey, C. L. Sheffield, T. S. Edrington, T. R. Callaway, R. C. Anderson, D. L. Drinnon, R. L. Ziprin, H. M. Scott, and D. J. Nisbet. 2004. Campylobacter prevalence in lactating dairy cows in the United States. J. Food Prot. 67:1476-1479.

Holý, O., and S. Forsythe. 2013. Cronobacter species as emerging causes of healthcare-associated infection. J. Hosp. Infect. 86:169-177.

ISO (International Organization for Standardization). 1996. ISO 11290-1:1996: Microbiology of food and animal feeding stuffsHorizontal method for the detection and enumeration of Listeria monocytogenes - Part 1: Detection method. ISO, Geneva, Switzerland.

ISO (International Organization for Standardization). 2003. ISO 10273:2003 (Microbiology of food and animal feeding stuffs - Horizontal method for the detection of presumptive pathogenic Yersinia enterocolitica. ISO, Geneva, Switzerland.

Jacobs, C., P. Braun, and P. Hammer. 2011. Reservoir and routes of transmission of Enterobacter sakazakii (Cronobacter species) in a milk powder-producing plant. J. Dairy Sci. 94:3801-3810.

Jay, S., D. Davos, M. Dundas, E. Frankish, and D. Lightfoot. 2003. Salmonella. Pages 207-266 in Foodborne Microorganisms of Public Health Significance. 6th ed. A. D. Hocking, ed. Australian Institute of Food Science Technology (NSW Branch) Food Microbiology Group, Sydney, NSW, Australia.

Jenson, I., and C. J. Moir. 2003. Bacillus cereus and other Bacillus species. Pages 445-478 in Foodborne Microorganisms of Public Health Significance. 6th ed. A. D. Hocking, ed. Australian Institute of Food Science Technology (NSW Branch) Food Microbiology Group, Sydney, NSW, Australia.

Kirk, M. D., J. Gregory, and N. Brotohusodo. 2010. Surveillance of foodborne disease in Australia and disease associated with dairy products. Aust. J. Dairy Technol. 65:98-100.

Klena, J. D., C. T. Parker, K. Knibb, J. C. Innitt, P. M. L. Devane, S. T. Horn, W. G. Miller, and M. E. Knokel. 2004. Differentiation of Campylobacter coli, Campylobacter jejuni, Campylobacter lari, and Campylobacter upsaliensis by a multiplex PCR developed from the nucleotide sequence of the lipid A gene $\operatorname{lp} x A$. J. Clin. Microbiol. 42:5549-5557.

Linage, B., J. M. Rodríguez-Calleja, A. Otero, M. L. García-López, and J. A. Santos. 2012. Characterization of coagulase-positive staphylococci isolated from tank and silo ewe milk. J. Dairy Sci. 95:1639-1644.

Manser, P. A., and R. W. Dalziel. 1985. A survey of Campylobacter in animals. J. Hyg. (Lond.) 95:15-21.

Mehrotra, M., G. Wang, and W. M. Johnson. 2000. Multiplex PCR for detection of genes for Staphylococcus aureus enterotoxins, exfoliative toxins, toxic shock syndrome toxin 1 , and methicillin resistance. J. Clin. Microbiol. 38:1032-1035.

Milnes, A. S., I. Stewart, F. A. Clifton-Hadley, R. H. Davies, D. G. Newell, A. R. Sayers, T. Cheasty, C. Cassar, A. Ridley, A. J. C. Cook, S. J. Evans, C. J. Teale, R. P. Smith, A. McNally, M. Toszeghy, R. Futter, A. Kay, and G. A. Paiba. 2008. Intestinal carriage of verocytotoxigenic Escherichia coli O157, Salmonella, thermophilic Campylobacter and Yersinia enterocolitica, in cattle, sheep 
and pigs at slaughter in Great Britain during 2003. Epidemiol. Infect. 136:739-751.

Molloy, C., C. Cagney, S. O'Brien, C. Iversen, S. Fanning, and G. Duffy. 2009. Surveillance and characterisation by pulsed-field gel electrophoresis of Cronobacter species in farming and domestic environments, food production animals and retail foods. Int. J. Food Microbiol. 136:198-203.

Muehlherr, J. E., C. Zweifel, S. Corti, J. E. Blanco, and R. Stephan. 2003. Microbiological quality of raw goat's and ewe's bulk-tank milk in Switzerland. J. Dairy Sci. 86:3849-3856.

New South Wales Food Authority (NSWFA). 2009. Food safety risk assessment of NSW food safetyschemes. Accessed Jul.27, 2014.http://www foodauthority.nsw.gov.au/_Documents/science/Food_Safety_ Scheme_Risk_Assessment.pdf.

Oliver, S. P., B. M. Jayarao, and R. A. Almeida. 2005. Foodborne pathogens in milk and the dairy farm environment: Food safety and public health implications. Foodborne Pathog. Dis. 2:115129

Oliver, S. P., and S. E. Murinda. 2011. Milk and raw milk consumption as a vector for human disease. Pages 99-118 in Zoonotic Pathogens in the Food Chain. D. O. Krause and S. Hendrick, ed. CAB International, Wallingford, UK.

Osaili, T. M., A. A. Al-Nabulsi, M. H. Taha, M. A. Al-Holy, A. R. Alaboudi, W. M. Al-Rousan, and R. R. Shaker. 2012. Occurrence and antimicrobial susceptibility of Listeria monocytogenes isolated from brined white cheese in Jordan. J. Food Sci. 77:M528-M532.

OzFoodNet Working Group. 2012. Monitoring the incidence and causes of diseases potentially transmitted by food in Australia: Annual report of the OzFoodNet Network, 2010. Commun. Dis. Intell. Q. Rep. 36:E213-E241.

Paton, A. W., and J. C. Paton. 2002. Direct detection and characterization of Shiga toxigenic Escherichia coli by multiplex PCR for $s t x_{1}$, stx, eae, ehxA, and saa. J. Clin. Microbiol. 40:271-274.

Perelle, S., F. Dilasser, J. Grout, and P. Fach. 2004. Detection by 5'-nuclease PCR of Shiga-toxin producing Escherichia coli O26, O55, O91, O103, O111, O113, O145 and O157:H7, associated with the world's most frequent clinical cases. Mol. Cell. Probes 18:185-192.

Quigley, L., O. O'Sullivan, C. Stanton, T. P. Beresford, R. P. Ross, G. F. Fitzgerald, and P. D. Cotter. 2013. The complex microbiota of raw milk. FEMS Microbiol. Rev. 37:664-698.

Roberson, J. R., L. K. Fox, D. D. Hancock, J. M. Gay, and T. E. Besser. 1994. Ecology of Staphylococcus aureus isolated from various sites on dairy farms. J. Dairy Sci. 77:3354-3364.

Rodriguez, A., P. Pangloli, H. A. Richards, J. R. Mount, and F. A. Draughon. 2006. Prevalence of Salmonella in diverse environmental farm samples. J. Food Prot. 69:2576-2580.

Schilling, A. K., H. Hotzel, U. Methner, L. D. Sprague, G. Schmoock, H. El-Adawy, R. Ehricht, A. C. Wöhr, M. Erhard, and L. Geue. 2012. Zoonotic agents in small ruminants kept on city farms in southern Germany. Appl. Environ. Microbiol. 78:3785-3793.

Schmid, M., C. Iversen, I. Gontia, R. Stephan, A. Hofmann, A. Hartmann, B. Jha, L. Eberl, K. Riedel, and A. Lehner. 2009. Evidence for a plant-associated natural habitat for Cronobacter species . Res. Microbiol. 160:608-614.

Seo, K.-H., and R. E. Brackett. 2005. Rapid, specific detection of Enterobacter sakazakii in infant formula using real-time PCR assay. J. Food Prot. 68:59-63.
Standards Australia. 2004a. AS 5013.6-2004: Food microbiology. Method 6: Examination for specific organisms-Campylobacter. Standards Australia, Sydney, Australia.

Standards Australia. 2004b. AS 5013.12.1-2004: Food microbiology. Method 12.1: Microbiology of food and animal feeding stuffsHorizontal method for the enumeration of coagulase-positive staphylococci (Staphylococcus aureus and other species)-Technique using Baird-Parker agar medium. Standards Australia, Sydney, Australia.

Standards Australia. 2006. AS 5013.16-2006: Food microbiology. Method 16: Microbiology of food and animal feeding stuffs-horizontal method for the enumeration of Clostridium perfringens Colony-count technique. Standards Australia, Sydney, Australia.

Standards Australia. 2007. AS 5013.2-2007: Food microbiology. Method 2: Microbiology of food and animal feeding stuffs - Horizontal method for the enumeration of Bacillus cereus - Colony-count technique at $30^{\circ} \mathrm{C}$ (ISO 7932:2004, MOD). Standards Australia, Sydney, Australia.

Standards Australia. 2010. AS 5013.13(Int)-2010: Food microbiology. Method 13: Milk and milk products-Detection of Enterobacter sakazakii. Standards Australia, Sydney, Australia.

Stewart, C. M. 2003. Staphylococcus aureus and Staphylococcal Enterotoxins. Pages 359-380 in Foodborne Microorganisms of Public Health Significance. 6th ed. A.D. Hocking, ed. Australian Institute of Food Science Technology (NSW Branch) Food Microbiology Group, Sydney, NSW, Australia.

Sutherland, P. S., D. W. Miles, and D. A. Laboyrie. 2003. Listeria monocytogenes. Pages 381-444 in Foodborne Microorganisms of Public Health Significance. 6th ed. A. D. Hocking, ed. Australian Institute of Food Science Technology (NSW Branch) Food Microbiology Group, Sydney, NSW, Australia.

Thisted Lambertz, S. C. Nilsson, S. Hallanvuo, and M. Lindblad. 2008. Real-time PCR method for detection of pathogenic Yersinia enterocolitica in food. Appl. Environ. Microbiol. 74:6060-6067.

Toth, J. D., H. W. Aceto, S. C. Rankin, and Z. Dou. 2013. Short communication: Survey of animal-borne pathogens in the farm environment of 13 dairy operations. J. Dairy Sci. 96:5756-5761.

USDA-FSIS (Food Safety and Inspection Service). 2012a. PCR platform instructions, data analysis, and control results interpretation for nonO157 Shiga Toxin-Producing Escherichia coli (STEC) Real-time PCR Assay. Accessed Jul. 22, 2014. http://www.fsis.usda.gov/wps/ wcm/connect/f6ebcc50-1e34-4aba-802b-38c5e720168e/MLG-5BAppendix-3.pdf?MOD=AJPERES.

USDA-FSIS (Food Safety and Inspection Service). 2012b. Food Safety and Inspection Service. Shiga toxin-producing Escherichia coli in certain raw beef products. Docket No. FSIS2010-0023. Accessed Sep. 17, 2014. https://www.federalregister. gov/articles/2012/05/31/2012-13283/shiga-toxin-producingescherichia-coli-in-certain-raw-beef-products.

Vautor, E., G. Abadie, J. M. Guibert, C. Huard, and M. Pépin. 2003. Genotyping of Staphylococcus aureus isolated from various sites on farms with dairy sheep using pulsed-field gel electrophoresis. Vet. Microbiol. 96:69-79.

Wang, R.-F., W.-W. Cao, and C. E. Cerniglia. 1997. A universal protocol for PCR detection of 13 species of foodborne pathogens in foods. J. Appl. Microbiol. 83:727-736. 